University of Wollongong

Research Online

Faculty of Law, Humanities and the Arts Papers (Archive)

Faculty of Arts, Social Sciences \& Humanities

$1-1-2017$

\title{
Is the Montreal Protocol a model that can help solve the global marine plastic debris problem?
}

Karen Raubenheimer

University of Wollongong, kraubenh@uow.edu.au

Alistair Mcllgorm

University of Wollongong, amcilgor@uow.edu.au

Follow this and additional works at: https://ro.uow.edu.au/lhapapers

Part of the Arts and Humanities Commons, and the Law Commons

Research Online is the open access institutional repository for the University of Wollongong. For further information contact the UOW Library: research-pubs@uow.edu.au 


\title{
Is the Montreal Protocol a model that can help solve the global marine plastic debris problem?
}

\author{
Abstract \\ The impacts of plastic debris on the marine environment have gained the attention of the global \\ community. Although the plastic debris problem presents in the oceans, the failure to control land-based \\ plastic waste is the primary cause of these marine environmental impacts. Plastics in the ocean are \\ mainly a land policy issue, yet the regulation of marine plastic debris from land-based sources is a \\ substantial gap within the international policy framework. Regulating different plastics at the final product \\ level is difficult to implement. Instead, the Montreal Protocol may serve as a model to protect the global \\ ocean common, by reducing the production of virgin material within the plastics industry and by \\ regulating both the polymers and chemical additives as controlled substances at a global level. Similar to \\ the Montreal Protocol, national production and consumption of this virgin content can be calculated, \\ providing an opportunity for the introduction of phased targets to reduce and eliminate the agreed \\ substances to be controlled. The international trade of feedstock materials that do not meet the agreed \\ minimum standards can be restricted. The aim of such an agreement would be to encourage private \\ investment in the collection, sorting and recycling of post-consumer material for reuse as feedstock, \\ thereby contributing to the circular economy. The proposed model is not without its challenges, \\ particularly when calculating costs and benefits, but is worthy of further consideration by the international \\ community in the face of the global threats posed to the ocean by plastics.

\section{Disciplines} \\ Arts and Humanities | Law

\section{Publication Details} \\ K. Raubenheimer \& A. Mcllgorm, 'Is the Montreal Protocol a model that can help solve the global marine \\ plastic debris problem?' (2017) 81 Marine Policy 322-329.
}




\title{
Is the Montreal Protocol a model that can help solve the global marine plastic debris problem?
}

\begin{abstract}
:
The impacts of plastic debris on the marine environment have gained the attention of the global community. Although the plastic debris problem presents in the oceans, the failure to control land-based plastic waste is the primary cause of these marine environmental impacts. Plastics in the ocean are mainly a land policy issue, yet the regulation of marine plastic debris from land-based sources is a substantial gap within the international policy framework. Regulating different plastics at the final product level is difficult to implement. Instead, the Montreal Protocol may serve as a model to protect the global ocean common, by reducing the production of virgin material within the plastics industry and by regulating both the polymers and chemical additives as controlled substances at a global level. Similar to the Montreal Protocol, national production and consumption of this virgin content can be calculated, providing an opportunity for the introduction of phased targets to reduce and eliminate the agreed substances to be controlled. The international trade of feedstock materials that do not meet the agreed minimum standards can be restricted. The aim of such an agreement would be to encourage private investment in the collection, sorting and recycling of post-consumer material for reuse as feedstock, thereby contributing to the circular economy. The proposed model is not without its challenges, particularly when calculating costs and benefits, but is worthy of further consideration by the international community in the face of the global threats posed to the ocean by plastics.
\end{abstract}

Keywords: marine plastic debris; marine litter; international policy; circular economy; Montreal Protocol; land-based sources

Highlights:

- A new international legally binding instrument for marine plastic debris is modelled

- This instrument would regulate land-based sources of marine plastic debris

- Improved collection, sorting and recycling of plastics is incentivised

- The Montreal Protocol provides a model that includes industry consultation

\section{Introduction}

Plastic waste pollutes every ocean and can enter the marine environment from land and from ocean sources. Marine plastic debris ranges from industrial plastic waste to litter and derelict synthetic fishing gear. [1,2] In the oceans, plastic can float, sink or remain in suspension and can be transported long distances from the point of entry into the marine environment. The impacts of this pollutant on marine species are well documented and include ingestion, entanglement and habitat degradation. Research has recently begun focussing on the leaching of additives from plastics, as well as the uptake of chemicals by plastics from the surrounding seawater. [3] These sorbed chemicals and those added during the manufacture of plastic products can transfer to those organisms that ingest plastic waste. Ingestion has been documented from whales to microscopic organisms. The effects of plastics and the chemicals they transport on the marine food web and human health are still unclear. [4] 
The costs of removal by coastal communities, repairs to equipment and infrastructure and reduced harvests when target organisms are caught by derelict fishing gear, are some of the contributors to the socio-economic impacts of marine plastic debris. Tourism can also suffer when amenities are affected by plastic waste. $[5,6]$

Analysis has shown the international and regional policy response is inadequate in protecting the oceans from land-based sources of pollution, [7] particularly plastic waste. [8] Policy intervention has largely treated the issues of marine plastic debris as a failure of solid waste management practices. [9] (paragraph 218). Calls have been made to improve waste management infrastructure, particularly in developing countries, and to reduce per capita waste generation in order to reduce the volume of plastic leaked into the ocean from mismanaged waste streams. [10] Policy measures by government that would assist in achieving this have been suggested. [11] Delineation has begun to emerge between policy measures that provide a linear solution to the waste issue, such as waste-to-fuel and waste-toenergy, [12] and those that incentivise a circular materials flow throughout the lifecycle of plastic products. The business case for progressing from a linear waste approach to a circular economy for plastics has been outlined in a report by the World Economic Forum, Ellen MacArthur Foundation and McKinsey \& Company. [13] The report highlighted the need to explore the overall enabling role that policy can play in incentivising such a circular economy, increasing the involvement of industry in controlling plastic production that may eventually enter the sea.

The model proposed here refers to four types of recycling based on the linear or circular lifecycle they deliver. [24] The objective of the model is to incentivise primary and tertiary recycling because of their contribution to a circular materials flow, thereby reducing the need for virgin feedstocks. Secondary and quaternary recycling are regarded as interim mitigation measures that reduce the contribution of marine plastic debris to the current stock, but do not reduce the long-term need for virgin feedstocks.

This paper is a first attempt at modelling a new international legally binding instrument that consults with industry to work towards a circular materials flow within the broader goal of a circular economy. The global nature of the issue lends itself to an international approach to ensure the efforts in one region are not negated by continued pollution in another region. Industry is increasingly voicing support for improved recycling of all types of plastics, supported by stable regulatory frameworks. [14-16]

The international community has several options to remedy this lack of an international instrument. The first option provides for the amendment of existing international instruments to ensure all the sources and impacts of the many plastic products on the market today and in the future are included in their scope.

The second option is to negotiate a new international legally binding instrument to regulate the plastics industry at a global level. The Law of the Sea Convention provides enabling Articles to support the establishment of such an agreement. Similar to the 1995 Fish Stocks Agreement, a new international instrument could be established as a third implementing agreement of the provisions in the Law of the Sea Convention, relating to the prevention of pollution of the marine environment from land-based sources. 
The third option is to negotiate a new 'stand-alone' agreement independent of the Law of the Sea Convention. In this paper, the potential for the use of the Montreal Protocol is investigated [17] to address plastic production on land (see Figure 1). This would allow for greater control of the lifecycle of plastic, from production through to treatment, and reducing their impacts on the oceans.

\section{Amend Existing Frameworks or Develop a New International Legally Binding Instrument?}

A number of existing multilateral environmental agreements provide a broad mandate for States to regulate marine plastic debris. Those with direct application include the UN Law of the Sea Convention, as well as the range of UN Regional Seas Conventions and their respective Protocols to prevent land-based sources of marine pollution. The Basel Convention on the Control of Transboundary Movements of Hazardous Wastes and Their Disposal and the Stockholm Convention on Persistent Organic Pollutants could also be considered, as well as the Convention on Biological Diversity.

The Law of the Sea Convention promotes a cooperative approach, mandating that States "endeavour" to establish global and regional rules and standards to combat land-based pollution (Article 207(4)). However, implementation has been fragmented with fourteen of the eighteen Regional Seas Programmes adopting a binding framework in the form of an overarching Convention to protect the shared marine environment. Of these, six have adopted Protocols for land-based sources of pollution that are in force and four are still pending. Eight regions therefore have no binding agreement specifically applicable to land-based sources of marine plastic debris. The length of time to amend these frameworks and the varying regional approaches are unlikely to yield the global standards in the timeframes required.

The mandate of the UN Regional Seas Programmes does not extend to the regulation of the global lifecycle of the plastics industry from design to final treatment. Similarly, the Basel Convention, Stockholm Convention and the Convention on Biological Diversity do not provide the mandate or scope to regulate all sources, trade and impacts of plastic products.

A new agreement could give effect to the Law of the Sea Convention, particularly Articles 192, 194, 207, 210, 213 and 216 of Part XII Protection and Preservation of the Marine Environment. These Articles establish a global mandate for States to protect and preserve the marine environment from all sources, to prevent transboundary pollution and the transformation of pollution into another form, to protect threatened species and to prevent the introduction of alien species. In addition, compliance with Articles 210 (ocean dumping) and Article 211 (vessel-based pollution) would result in plastic waste being disposed of on land instead of the marine environment.

The Law of the Sea Convention is the only instrument that provides the mandate for the prevention of marine plastic debris on a global scale. The objective of this agreement is the protection and preservation of the marine environment, supported by the Convention on Biological Diversity. This does not necessarily extend to the protection of terrestrial environments or human health from the many effects of plastic waste and the chemical additives they contain. 
The approach proposed for a new instrument is to manage the global plastics industry without the need to classify plastics as a hazardous substance, as would be required under the Basel Convention and the Stockholm Convention. A secondary objective of this agreement would be a reduction in the symptoms experienced by marine ecosystems. This is a difficult target to measure, whereas compliance with the proposed Montreal Protocol approach can be more easily defined and monitored by all States with varying economies.

\section{Why the Montreal Protocol?}

The OECD suggests that the concept of Sustainable Materials Management requires "a shift from policies focused on isolated aspects of the material chain, causing leakages and unintended side effects, to an integrated policy approach that embraces the full life cycle of products and materials." This will require "a long term vision that provides a framework for policy making and investment, with a clear set of measurable objectives." [18]

The development of international policy is more advanced for ocean-based sources of marine plastic debris than for land-based sources. This discussion suggests a new international legally binding instrument to prevent land-based sources of marine plastic debris may be based on the primary elements of the Montreal Protocol. ${ }^{1}$ [19] This Protocol was designed to address depletion of the ozone layer in the atmosphere, which is a common pool analogous to the oceans. The Protocol is widely regarded as the most successful multilateral agreement in resolving an environmental issue, mostly due to its level of participation, the global cooperation generated and the targets achieved, amongst other factors. [20, 21] It also serves as an example of industry taking responsibility for the environmental impacts of the products they produce. Can it also serve as a model to regulate the environmental impacts of plastic products?

The Protocol could provide a model to overcome the complexities of regulating plastics at the final product phase or as a waste product, instead targeting the feedstock level. The flexibility incorporated into the Montreal Protocol has allowed it to accommodate advancements in science as well as technologies to recycle and reduce chemicals in use or in storage where they are no longer compliant.

This flexibility is achieved through mandatory regular assessment and review of the control measures, [17] (Article 6) including the addition or removal of any substances [17] (Article 11(4.a-c, h, j)) as advised by technical experts. Amendments that constitute a new obligation must be adopted within the provisions of Article 2. Once adopted, these decisions are binding on all Parties, [17] (Article 2(9.d)) whereas adjustments automatically enter into force for all Parties. Non-Parties are encouraged to attend meetings of the Parties and to comply with the provisions of the Protocol. [17] (Article 12(e))

The scientific evidence of harm to the ozone was sufficient to trigger the Precautionary Principle, if not the Prevention Principle. In the case of the oceans, the harmful effects to humans of plastics and their chemical additives must still be proven within the spectrum of realistic exposure rates. There is, however, a plethora of evidence of harm to the environment

\footnotetext{
${ }^{1}$ It has previously been suggested that the Montreal Protocol could serve as an example instrument to consider when designing a new legally binding international agreement to regulate marine plastic debris. The elements of such an agreement were not detailed.
} 
by plastic waste, which may eventually extend to impacts on populations of marine creatures and long-term food security for humans. Even without conclusive evidence of the latter, it can be argued that the known impacts of plastic pollution are sufficient to invoke the Prevention Principle.

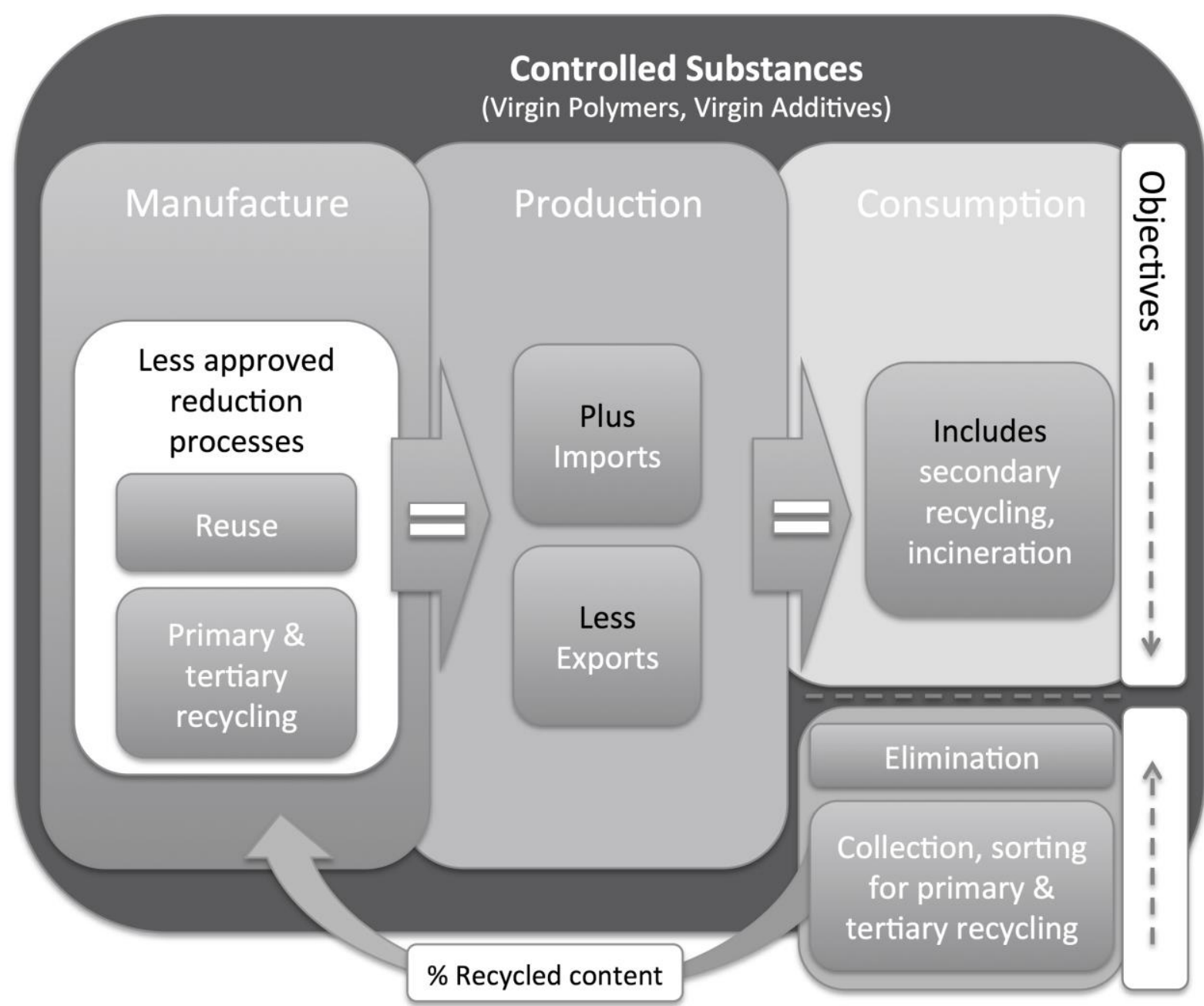

Figure 1: Applying Elements of the Montreal Protocol to Plastic Consumption

The diagram illustrates the calculations of national manufacture, production and consumption of the controlled substances (virgin plastic polymers and virgin chemical additives) and links them to the objectives of reducing the calculated national consumption, while increasing the elimination of harmful chemicals and products. A third objective can be achieved by mandating minimum recycled content in the manufacture of products, which in turn incentivises the collection of plastic waste and sorting as feedstock for primary and tertiary recycling processes. Secondary recycling and incineration are regarded as interim measures and do not reduce consumption levels long-term due to their linear lifecycle.

\section{What Could a New International Legally Binding Instrument Look Like?}

A new agreement should transition from regulating marine plastic debris as a failing in municipal solid waste services to the preventive approach in which the role of industry and the plastics supply chain is central. This can be achieved by regulating the feedstocks of plastic products as a controlled substance. In particular, the use of virgin material must be 
constrained and the use of post-consumer materials promoted. The elements of the proposed instrument are illustrated in Figure 1.

\subsection{Objective}

The objectives of a new agreement would be threefold: 1) to reduce the production of virgin material used in plastic production, both polymers and chemical additives, 2) eliminate the use of harmful chemicals, and 3) provide legislative support to stabilise and grow the recycling industry. This, in turn, would encourage investment in collection and sorting services to provide quality post-consumer material in a robust market.

The Preamble of the Montreal Protocol promotes the regulation of the controlled substances be based on relevant scientific knowledge and remain current with new developments in such knowledge. A new agreement for plastics should take this further by including the requirement for product design that is compatible with current and future collection, sorting and recycling technologies.

A circular material flow for plastics relies heavily on the recycling of waste. It also requires linking product design to recycling technologies. The Association of Postconsumer Plastic Recyclers suggests that for an item to be considered truly recyclable, not only must it have the ability to be processed through a typical recycling system, but it must also be possible to sort and separate the item through commonly used recovery systems, with a minimum of $60 \%$ of consumers having access to a collection system that accepts the item. [22]

The overall ease of recycling plastic products would be an important objective of a new agreement. This includes the chemical components of the product. Reducing the number of products that are too complicated for available sorting and recycling facilities will reduce the percentage of waste products destined for landfill, dumping or incineration.

\subsection{Controlled Substances}

The ozone-depleting substances regulated by the Montreal Protocol are listed in four Annexes to the Protocol. A controlled substance is defined as one of these listed substances, "whether existing alone or in a mixture." [17] (Article 1(4)) Further clarification is given on their isomers and their inclusion in manufactured products. The Basel Convention Guidelines for the management of plastics [23] (Table 1: Common Polymers) lists eight plastic groups. This may serve as a basis for categorisation under a new international legally binding instrument to regulate plastic production.

Additionally, a new agreement should control the chemical component of plastics. Common chemical additives for plastic were listed in a 2016 UNEA report. [4] (Annex) This list, as well as the list of plastic polymer types, could assist in developing control measures specific to the main categories, similar to Article 2 of the Montreal Protocol.

The definition of controlled substance should apply only to virgin polymers and additives destined for use in the production of plastic products. Negotiators must make it clear that this applies to primary plastics manufacturers that produce pre-production plastic pellets as well as conversion facilities where pellets are combined with additives and modifiers to make 
useful products. Conversion facilities may include shredded and other recycled content in the manufacturing process. Any other processes that contribute to the production of a final product released to market should also be considered.

\subsection{Production and Consumption}

The Montreal Protocol provides methods for calculating levels of national production, imports, exports and consumption. [17] (Article 3) Production is defined as the amount of controlled substances produced, less the amount destroyed by approved technologies. Controlled substances that are recycled or reused are not to be included in the calculation of production levels. [17] (Article 1(5)). Similarly, a new agreement that aims to advance circular material flows within the global plastic industry should define production as the amount of virgin material produced and exclude recycled polymers and additives in these calculations. Approved reduction processes are discussed below (see also Figure 1). Consumption of controlled substances is defined in the Montreal Protocol as "production plus imports minus exports." [17] (Article 1(6))

Article 3 of the Montreal Protocol provides further detail on the calculation of production, imports/exports and consumption. The varying potential of the controlled substances to deplete the ozone is taken into account. A rating per substance is to be multiplied by the annual production of that substance. The results are added together for each group and used to determine the reduction targets and caps as per Article 2. The same procedure applies to calculating the levels of controlled substances imported and exported. Consumption levels are then calculated using these results, but States are not permitted to subtract the export of controlled substances to non-Parties (as of 1 January 1993). Such calculations may be applicable to the chemical additives used in certain plastics to reflect their varying potential to cause environmental or human harm. An example is PVC, which is regarded as more toxic than other plastic types.

\subsection{Targets and Caps}

A new international agreement to address land-based sources of marine plastic debris would need to set clear and enforceable pollution standards. [7] Once the thresholds of pollution are determined, further control measures such as reduction targets and caps can be calculated.

Article 2 of the Montreal Protocol groups the control measures, currently listing nine groups from chlorofluorocarbons (CFCs) to Bromochloromethane. [17] (Article 2(A-I)) These groups are further elaborated in the Annexes. Targets range from phased reductions over a number of years, relative to calculations for an agreed baseline year, to a zero production and consumption target as of a specified year. Provisions are made in some groups for agreed uses that are exempted from control. The aim is to enforce conversion to alternative substances that are less harmful.

The objective of setting targets in a new agreement would be to cap the global consumption of plastic resins made from $100 \%$ virgin feedstock. Control measures should establish broad categories of plastics and additives, as suggested above. It may be necessary to further subdivide categories by industry, application or product longevity. For instance, plastic incorporated into cars and buildings would have a longer lifespan than plastic used in 
packaging. Single-use plastics should require a higher percentage of post-consumer material and be designed for easy collection, sorting and recyclability. As technologies and product design evolve, a new international legally binding instrument should aim to gradually increase the post-consumer content contained within plastic products, but also eliminate harmful products.

Legislation that mandates a minimum content of recycled material can significantly increase demand for secondary feedstock and assist in maintaining a positive cash flow for the recycling industry when the price of commodities decrease. Recycling rates for paper, iron and steel are significantly higher than plastics, reaching $90 \%$ in some cases. [13] (p. 26) Efforts must be made to raise the global recycling rate of plastics above the estimated $5 \%$.

Targets and caps adopted in the Montreal Protocol are mostly constructed on baseline years. Applying the concept to marine plastic debris would require negotiators to first agree a baseline production year [18] of virgin resins from which percentage reduction targets can be designed. Such calculations and their compliance timeframes would need to consider the lag in rectifying issues in current solid waste management services. This includes upgrades to collection and sorting services, as well as recycling infrastructure and technologies. However, the ambition of these targets and the urgency of their adoption should take into account the longevity of leaked plastic waste that would continue in the absence of such measures.

The model of close cooperation with industry provided by the Montreal Protocol is more appropriate to solving the problem of plastic waste than the use of black, white and grey lists employed in the London Dumping Protocol, the Stockholm Convention and the Basel Convention. However, the London Dumping Protocol may be a useful model for the regulation of chemical additives used in the production of plastics. The use of additives known to have unacceptable impacts on individual species, ecosystems and humans could be prohibited, while allowing the use of safe chemicals outlined on a white list. [7] The use of synthetic substances outside of that white list would be subject to an agreed impact assessment procedure and a license or permit. The basis of these lists and procedures would be the ecological impact as well as the ease with which controlled substances can be recycled. Chemicals in existing products that would contaminate post-consumer feedstock should be black listed.

\subsection{Setting Measurable Targets}

The Montreal Protocol provides stronger language when setting targets than the existing international instruments applicable to marine plastic debris. The Law of Sea Convention provides no measurable targets for preventing marine pollution. States are only required to use "the best practicable means at their disposal and in accordance with their capabilities." [47] (Article 194) Domestic legislation for land-based sources of marine pollution needs only 
"take into account" international standards. [47] (Article 207(1)) The voluntary Honolulu Strategy sets no targets for marine litter and the Global Programme of Action provides subjective targets of "reduce significantly." [48] (Para. 144(b)) In contrast, the Montreal Protocol requires that "each Party shall ensure" specified targets are met. [17] (Article 2) Similar examples can be found in the Conventions of the Baltic and North-East Atlantic Seas, which require all appropriate or possible steps be taken to "prevent and eliminate pollution" from land-based sources. [49] (Article 6(1)), [50] (Article 3) In addition, the Stockholm Convention commits Parties to "prohibit and/or take the legal and administrative measures necessary to eliminate" the production, use, import and export of those substances controlled by the Convention. [51] (Article 3(1))

\subsection{Approved Reduction Processes}

Regular meetings of the Parties to the Montreal Protocol include reviewing the approved destruction processes. As per the definition of production of controlled substances, the recycling or reuse of these substances is not included in calculations of national production. [17] (Article 1(5)) A similar application would be appropriate for plastic polymers and chemical additives. A distinction must, however, be made between the four types of recycling for plastics, as described by Hopewell et al. [24]

Primary recycling provides a circular material flow where the recycled product has similar qualities to the original, [24] generally requiring a high standard of waste feedstock. Secondary recycling results in a product of lower properties, a process often referred to as downgrading because the resulting products mostly cannot be recycled again. [24] Tertiary recycling involves the recovery of the chemical constituents of a plastic product, whereas quaternary recycling is the incineration of plastic waste to recover the energy stored in the product. [24]

Secondary recycling is commonly used [13] (p. 26) and, while this will reduce the requirement to produce virgin polymers in the short term, the contribution of such processes to a circular materials flow will apply to limited generations of products. Eventually the secondary product is likely to be landfilled or incinerated. Similarly, producing energy from waste would represent a linear process and would not reduce the demand for virgin feedstock.

Under a new agreement, plants that incinerate plastic waste for energy should be allowed to operate if built prior to a specific date and if they comply with agreed environmental controls. $[13,25-28]$ These should only be permitted to destroy plastic products that cannot be recycled. Approval for such reduction processes may need to remain in place until all plastics produced are capable of primary and tertiary recycling processes and possibly until all existing plastic waste on land and in the oceans has been recovered, where achievable. Incineration would therefore be a transitional solution.

\subsection{Trade Restrictions}

The use of trade restrictions in multinational agreements helps regulate environmentally harmful trade, but can also induce participation, broaden control measures and assist in ensuring compliance amongst signatories. [29] Trade restrictions must aim to reduce any economic advantage generated for facilities in non-participating States that are not subject to 
the environmental controls established by the agreement.

Trade restrictions were included in the Montreal Protocol as one of the primary mechanisms to achieve the goals of the agreement by preventing leakage of controlled substances to nonparticipatory States. [17] (Article 4) Additionally, these sanctions provided an incentive for non-signatory States to participate in the agreement, thus assisting in reducing the consumption of ozone depleting substances not only at the domestic level, but also at the global level. [20] (p. 322) Measures ranged from banning the import and export of particular controlled substances from any State not party to the Protocol [17] (Article 4(1, 2)) to creating lists of products containing those controlled substances and banning their import and export. [17] (Article 4(3)) The Protocol also aimed to restrict any financial support such as subsidies and credits if these contributed to the export of product, equipment, plants or technology used in the production of all controlled substances in non-Party States. [17] (Article 4(5)). These measures are in addition to the requirement by Parties to license the import and export to any other State of certain new, used, recycled and reclaimed controlled substances. [17] (Article 4B)

UNEP suggests four main categories to include when designing trade measures. They should also be specific so as to avoid conflict with international trade law. The four categories are 1) ensuring the integrity of regulatory frameworks, 2) geopolitical containment of the issue, 3) restricting the market for undesirable products and 4) ensuring compliance. [30] These are important in the context of plastics manufacturing, particularly where production is reportedly outpacing demand in some Asian States resulting in an oversupply of plastic resins. [31] Oversupply can lead to lower prices for virgin plastic resin pellets, making these States reluctant to agree to trade restrictions on materials with no post-consumer content. Negotiations would need to consider the current stock of raw materials that do not meet the agreed minimum standards, possibly assisting with funding to reprocess these materials to include the required minimum post-consumer materials.

\subsection{Reporting and Urgency of Initiating Compliance}

In recognition of the urgency to bring the consumption of CFCs under control, all Parties to the Montreal Protocol consented to a binding obligation to limit their consumption of these controlled substances to levels equal to or below their calculated levels for the year the Protocol was adopted. This was for the twelve-month period beginning seven months after the Protocol came into force. With the Protocol coming into force on the $1^{\text {st }}$ January 1989 , this effectively gave early adopters less than sixteen months to halt any increase in the combined level of production and import of CFCs. [17] (Article 2A)

Parties to the Protocol are to provide annual reports on their production of the controlled substances, including amounts used for feedstocks, amounts destroyed by approved processes and all imports and exports to both parties and non-Parties. [17] (Article 7) Similarly, Parties to a new international legally binding instrument for plastics could report annually on production, import and export of virgin materials, as well as use, import and export of postconsumer material. Export of virgin material should be controlled by the Secretariat of the new agreement.

\subsection{Technology Transfer and Capacity Building}


The Montreal Protocol provides for the sharing of research, development, public awareness and exchange of information. [17] (Article 9) This is also important within the lifecycle of plastics from product design, collection, sorting and recycling to the management of chemical additives. Shared research should include the impacts of product components, as well as methods for measuring the effectiveness of control strategies and their costs versus their benefits. This is particularly true for countries in need of assistance where the costs of upgrading waste and recycling facilities may be prohibitive.

\section{Discussion}

Recycling targets for plastic waste are not a new concept. These were included in the 1994 EU Packaging and Packaging Waste Directive [32] (Article 6(1)), following targets set in the EU Circular Economy Package. Minimum postconsumer content legislation for rigid plastic packaging containers and plastic trash bags was also enacted in California in 1991. [33] (Chapter 5.5, Article 2 [42310], Chapter 5.4 [42291(2.A)]) Sustainable procurement policies have also been promoted to stimulate the consumption of recycled plastic products. [34] (Article 9(3.b)). The US State of California requires all public agencies to ensure by 2020 that recycled products constitute at least $50 \%$ of the reportable purchases. [35] (Article 4. Recycled Materials, Goods, and Supplies [12203, 12209(f)(1)]) The EU Waste directive promotes repair, re-use and disassembly, as well as recycling. [36] The 2015 EU Action Plan for the Circular Economy included developing quality standards for secondary raw materials, particularly plastics, as well as a strategy on plastics in the circular economy. [37] Products such as plastic cans with metal lids and aseptic packaging have been banned because they are not easily recyclable. [38]

Plastic additives have also been regulated before. France banned the use of Bisphenol A (BPA) in in all packaging, containers and utensils intended to come into direct contact with food, [39] as have other States to varying degrees. [40] The EU has regulated the plastic materials that can come into contact with foodstuffs. [41] Phthalates, a common plasticiser, have also been regulated. [42] A non-binding resolution was adopted by the European Parliament suggesting that articles containing a previously banned phthalate be prohibited from being recycled in the EU because of the health risks to workers in recycling facilities. [43]

These examples provide confidence that designing a new international legally binding instrument to prevent marine plastic debris based on the Montreal Protocol may reinforce past policies on regulating plastics. Applying the elements of the Montreal Protocol can shift the dominant design of policy responses from end-of-life waste management and product bans [11] towards a circular materials flow for the plastics industry. These discussions are aspiring but worthwhile as efforts to date for managing this global pollutant have been fragmented and public expectations of an industry solution are growing. [4] 
Using the Montreal Protocol as a model to reduce the levels of plastic in the oceans is not without its challenges. This would require considerable intergovernmental and industry consultations. Industry has indicated willingness for such a process to occur. [14-16] There are further considerations for such an ambitious undertaking.

\subsection{Cost Benefit Analysis}

The use of the Montreal Protocol as a comparative agreement raises the issue of the costs of implementation. A cost-benefit analysis for the regulation of the plastics industry may not be as favourable as calculations for global conversion to ozone-friendly substances proved. The cost of infrastructure required to solve the plastic waste issues are likely much higher than the costs of reducing and eliminating ozone-depleting substances. The Preamble of the Montreal Protocol also reminds us that "the magnitude of funds necessary is predictable, and the funds can be expected to make a substantial difference in the world's ability to address the scientifically established problem of ozone depletion and its harmful effects." [17] A clearer understanding is needed of the harmful impacts of plastics and their chemical additives on humans, fish populations and food security to allow for a comparative global cost-benefit estimate. This would have to include a broad range of costs and benefits, including ecosystem and environmental values. Only then can the costs of no-action be compared to the costs of implementing a new agreement, no matter which form it may take.

The use of targets and caps can lead to innovation and resource efficiency. By mandating the use of post-consumer plastics and additives, improvements in solid waste management can be stimulated by incentivising investment in collection and sorting services to support the recycling industry. The design criteria of new products manufactured domestically or imported could also be regulated to assist in linking product recyclability with recycling technologies. This may require programs of certification, coding or reporting. Design criteria may include the use of fewer polymer types, ease of disassembly and clear coding of each component for easy identification. [46]

\subsection{Technological Difficulties in Recycling}

Promoting the increased use of post-consumer content may seem an obvious progression, but is not as simple as reusing scrap material from a single product line. Recycling requires different types of machinery and technology depending on the material being recycled. Many products are made of multiple resins and additives, [23] (p. 9) such as multi-layered packaging. Technical issues include contamination, polymer degradation, quality of secondary materials and resin incompatibility. Recycled material intended for medical and food contact will be subject to stricter health regulations. Different percentages of post- 
consumer content may also be necessary for different industries. Examples include the plastic content used in vehicles, agriculture, construction and transport packaging.

Annexes or Protocols to the new agreement could make allowances for certain industries that are subject to stricter legislative controls. Similar consideration may be necessary for sectors that make use of products with a long lifespan. This would provide the time needed for the sectors involved to make the necessary technological improvements.

\subsection{Reintroduction of Banned Chemicals}

Additives previously used in the manufacturing process of older products may since have become restricted. Recycling these products may reintroduce banned chemicals into the market. [13] (p. 80) [44] The extraction of chemicals is also not an easy process. The timelines for compliance with a new multilateral agreement must therefore take into account the long-term investments of the waste industry. Contracts for the supply of waste may also be less flexible. Negotiations must therefore include close consultation with all sectors of the lifecycle of plastic products.

\subsection{Assessment of Alternative Chemicals}

The possibility exists that replacement for additives that become regulated may be more harmful than the original chemicals. At a 2016 meeting of the Parties to the Montreal Protocol, China suggested the establishment of an ad hoc standard coordinating group to consider standards for alternative chemicals. Issues relating to patents and royalties were raised, as well as changes to import costs. [45] A similar process could be considered for plastic additives.

\subsection{Industry Transition to Long-term Goals}

Policy interventions that have only diversion from landfill as an objective would encourage an increase in all forms of recycling (primary, secondary, tertiary or quaternary). Secondary and quaternary may be favoured by industry in the short term. Policy that promotes a circular materials flow for plastics must encourage primary and tertiary recycling. This would incentivise design modifications that make a product more easily recyclable. These include components and features that can be readily collected, accepted, and sorted at materials recycling facilities, thus improving the yield of operators. [22] The use of mandatory recycled content targets combined with the principles of Extended Producer Responsibility and the Polluter Pays could assist in achieving these long-term goals. 


\subsection{International Trade Concerns}

A multilateral agreement that regulates international trade must consider the rights of States that are party to the World Trade Organisation (WTO), as well as the WTO Agreement on Technical Barriers to Trade (TBT Agreement). Measures may be consistent with the General Agreement on Tariffs and Trade (GATT) Article XX exemptions, if they are considered "necessary to protect human, animal or plant life or health," or relate to "the conservation of exhaustible natural resources if such measures are made effective in conjunction with restrictions on domestic production or consumption." [52] (Article XX(b, g)) The impacts on biodiversity caused by plastic waste are now clear, and an annual consumption of $8 \%$ of global oil and gas production [24] may be regarded as sufficient for trade restrictions on traditional virgin resins to meet these criteria. Trade restrictions are also employed in the Rotterdam PIC Convention [53] and the Minamata Convention. [54]

\subsection{State Participation}

Participation in any new agreement may prove challenging and some have taken decades to come into force. For a new international agreement to regulate the consumption of virgin feedstocks in the global plastics industry, the participation of China, Europe ${ }^{2}$ and the NAFTA States $[55]^{3}$ would be vital. These regions were responsible for $24.8 \%, 20 \%$ and $19.4 \%$ of primary production respectively in 2013. [56]

Their participation would result in over $60 \%$ of global primary plastic production being regulated. In comparison, a new international legally binding instrument could aim to reduce mismanaged plastic waste at the end of the product lifecycle. A study by Jambeck et al indicated that, for such an agreement to come into force with a minimum participation rule of $50 \%$ of global annual mismanaged plastic waste, the participation of 168 of the 192 coastal States studied would be needed should China and Indonesia refrain. [10] Achieving such a high level of participation by countries with small volumes of plastic production would require strong incentives.

Trade restrictions proved successful in encouraging State participation for the Montreal Protocol. A similar approach, through cooperation by those States with high consumption rates, could be designed for a new agreement to regulate the majority of virgin feedstock consumption within the plastics industry.

\subsection{Contributing to Global Goals}

\footnotetext{
${ }^{2}$ Calculations included the EU27 States, Norway and Switzerland.

${ }^{3}$ NAFTA is a treaty entered into by the United States, Canada, and Mexico.
} 
The dominance of several large plastic producing nations may give the impression that much of the global issues of marine plastic debris could be substantially addressed through the national efforts of these nations. Negotiations may be impeded when a few nations are asked to bear environmental costs that may reduce the competitiveness of their products in international markets. The case for global action depends on both the extent to which the international community value the damage to the ocean environment by plastics and the link between ocean plastic pollution and human health. The approach based on the Montreal Protocol may be considered a suitable international model for collective global action that has addressed analogous issues with the global ozone problem.

Just as the Montreal Protocol has contributed to the goals of the Kyoto Protocol, so too can a new international legally binding instrument modelled on the Montreal Protocol assist in achieving the goals of the Convention on Biological Diversity and the Convention on Migratory Species, amongst others. The Principles of Precaution, Prevention and Polluter Pays can also be applied while realising cost savings for the plastics industry and providing social improvements through effective waste collection services.

Finally, a new agreement to regulate the plastics industry as proposed would assist in achieving a number of Sustainable Development Goals. The Goals provide for the reduction of marine pollution, particularly from land-based activities (SDG 14.1); avoid significant adverse impacts to marine and coastal ecosystems (SDG 14.2); improve water quality by reducing pollution and minimising the release of hazardous chemicals and materials (SDG 6.3); reduce the per capita environmental impact of cities through municipal and other waste management (SDG 11.6); achieve environmentally sound management of chemicals and all wastes throughout their lifecycle (SDG 12.4) and substantially reduce waste generation through prevention, reduction, recycling and reuse (SDG 12.5).

\section{Conclusion}

A new international legally binding instrument based on the Montreal Protocol would aim to increase the recycled rate of new and existing plastics by incentivising the supply of higher quality products in greater volumes to the recycling industry. In support of this, the aim would be to encourage design and material innovation to increase the recyclability of new products. At a broader level, reducing the use of virgin feedstocks must take into account the increasing demand for plastics globally.

Similar to the concerns of ozone depleting substances, marine plastic debris is an international problem that needs to be addressed at a global level. Without a policy framework that legislates the contribution industry can make, the onus will continue to be on the public sector to prove harm, non-compliance or unacceptable pollution levels and to provide the services necessary to prevent leakage of mismanaged waste. 
This article is intended as a starting point to the discussion on addressing the marine plastic debris problem through regulation of the plastics industry at a global level. The international community should investigate this approach more fully in its quest to prevent the flow of plastic debris into the world's oceans.

This research did not receive any specific grant from funding agencies in the public, commercial, or not-for-profit sectors.

References:

[1] G. Macfadyen, T. Huntington, R. Cappell, Abandoned, lost or otherwise discarded fishing gear, UNEP Regional Seas Reports and Studies, No. 185; FAO Fisheries and Aquaculture Technical Paper, No. 523, Rome, UNEP/FAO, Rome, 2009.

[2] United Nations Environment Programme (UNEP), Marine Litter: A Global Challenge, Nairobi, UNEP 2009.

[3] GESAMP, Proceedings of the GESAMP International Workshop on plastic particles as a vector in transporting persistent, bio-accumulating and toxic substances in the oceans, IMO/FAO/UNESCO-IOC/UNIDO/WMO/IAEA/UN/UNEP Joint Group of Experts on the Scientific Aspects of Marine Environmental Protection 2010.

[4] United Nations Environment Programme (UNEP), Marine plastic debris and microplastics - Global lessons and research to inspire action and guide policy change, United Nations Environment Programme, Nairobi 2016.

[5] United Nations Environment Programme (UNEP), Plastic Waste Causes Financial Damage of US\$13 Billion to Marine Ecosystems Each Year as Concern Grows over Microplastics.

<http://www.unep.org/newscentre/Default.aspx?DocumentID=2791\&ArticleID=10903\&l=en $>, 2014$ (accessed 10 June.2015).

[6] United Nations Environment Programme (UNEP), Valuing Plastics: The Business Case for Measuring, Managing and Disclosing Plastic Use in the Consumer Goods Industry, 2014. [7] D.L. VanderZwaag, A. Powers, The Protection of the Marine Environment from LandBased Pollution and Activities: Gauging the Tides of Global and Regional Governance, The International Journal of Marine and Coastal Law 23(3) (2008) 423-452.

[8] K. Raubenheimer, Towards an Improved Framework to Prevent Marine Plastic Debris, Australian National Centre for Ocean Resources and Security (ANCORS), University of Wollongong, Australia, 2016.

[9] UN General Assembly, The Future We Want, 66/288, 2012, p. 19.

[10] J.R. Jambeck, R.J. Jenna, G. Roland, W. Chris, R.S. Theodore, Plastic waste inputs from land into the ocean, Science (New York, N.Y.) 347(6223) (2015) 768-771.

[11] United Nations Environment Programme (UNEP), Marine Litter Legislation: A Toolkit for Policymakers, 2016.

[12] McKinsey Center for Business and Environment, Stemming the Tide: Land-based strategies for a plastic-free ocean, Ocean Conservancy 2015.

[13] World Economic Forum, Ellen MacArthur Foundation and McKinsey \& Company, The New Plastics Economy - Rethinking the future of plastics, 2016. 
[14] British Plastics Federation, Plastics Recycling.

<http://www.bpf.co.uk/sustainability/plastics_recycling.aspx>, 2016 (accessed 8

October.2016).

[15] Recycling International, Wish list to help create 'a true' Circular Economy.

$<$ http://www.recyclinginternational.com/recycling-news/9987/research-and-

legislation/europe/wish-list-help-create-039-true-039-circular-economy>, 2016 (accessed 13

October.2016).

[16] Recycling International, Plastics: 'plenty of disruptions'.

$<$ http://www.recyclinginternational.com/recycling-news/10009/plastic-and-

rubber/global/plastics-039-plenty-disruptions-039>, 2016 (accessed 21 October.2016).

[17] Montreal Protocol on Substances that Deplete the Ozone Layer, opened for signature 16 September 1987, [1989] ATS 18 (entered into force 1 January 1989) ('Montreal Protocol') <http://www.austlii.edu.au/au/other/dfat/treaties/1989/18.html>.

[18] Victor Dries, OECD Global Forum on Environment Focusing on Sustainable Materials Management: Chair's Summary, OECD Environment Directorate 2010.

[19] M. Gold, K. Mika, C. Horowitz, M. Herzog, L. Leitner, Stemming the Tide of Plastic Marine Litter: A Global Action Agenda, Emmett Center on Climate Change and the Environment, UCLA School of Law Pritzker Briefs(No. 5) (2013).

[20] S. Barrett, Environment and Statecraft: The Strategy of Environmental Treaty-Making, Oxford Scholarship Online 2005.

[21] Australian Government (Department of Environment), Montreal Protocol on Substances that Deplete the Ozone Layer. <https://www.environment.gov.au/protection/ozone/montrealprotocol>, 2015 (accessed 9 December.2015).

[22] Association of Postconsumer Plastic Recyclers (APR), The APR Design Guide for Plastics Recyclability. <http://www.plasticsrecycling.org/apr-design-guide/apr-design-guidehome>, 2015 (accessed 17 January.2016).

[23] United Nations Environment Programme (UNEP), Technical guidelines for the identification and environmentally sound management of plastic wastes and for their disposal (UNEP/CHW.6/21), 2002.

[24] J. Hopewell, R. Dvorak, E. Kosior, Plastics recycling: challenges and opportunities, Philosophical Transactions of the Royal Society B: Biological Sciences 364(1526) (2009) 2115-2126.

[25] S.M. Al-Salem, S. Evangelisti, P. Lettieri, Life cycle assessment of alternative technologies for municipal solid waste and plastic solid waste management in the Greater London area, Chemical Engineering Journal 244 (2014) 391-402.

[26] H. Merrild, A.W. Larsen, T.H. Christensen, Assessing recycling versus incineration of key materials in municipal waste: The importance of efficient energy recovery and transport distances, Waste Management (New York, N.Y.) 32(5) (2012) 1009-1018.

[27] A. Tukker, Plastics waste : feedstock recycling, chemical recycling and incineration, Shawbury, U.K. : Rapra Technology Ltd., 2002. 2002.

[28] C.-T. Li, H.-K. Zhuang, L.-T. Hsieh, W.-J. Lee, M.-C. Tsao, PAH emission from the incineration of three plastic wastes, Environment International 27 (2001) 61-67.

[29] Organisation for Economic Co-operation and Development (OECD), Trade Measures In Multilateral Environmental Agreements: Synthesis Report Of Three Case Studies, 1999. [30] International Institute for Sustainable Development \& United Nations Environment Programme, Trade and Green Economy: A Handbook, Published by the International Institute for Sustainable Development, Geneva 2014.

[31] ANZ Insights: Commercial Banking Asia, Global Plastics Industry: Market Update, 2012. 
[32] European Parliament and Council Directive 94/62/EC of 20 December 1994 on packaging and packaging waste, as amended, 1994, p. 11 February 2004.

[33] California Public Resources Code, Division 30, Part 3. State Programs.

[34] UNEP (DEPI), Regional Plan on Marine Litter Management in the Mediterranean in the Framework of Article 15 of the Land Based Sources Protocol (Decision IG.21/7), 2013, p. 8 July 2014.

[35] California Public Contract Code, Division 2, Chapter 4. State Agency Buy Recycled Campaign.

[36] Directive 2008/98/EC of the European Parliament and of the Council of 19 November 2008 on waste and repealing certain Directives, 2008, p. 19 November 2008.

[37] Communication from the Commission to the European Parliament, the Council, the European Economic and Social Committee and the Committee of the Regions. Closing the loop - An EU action plan for the Circular Economy (COM/2015/0614), 2015.

[38] Plastech, PET cans contaminate plastic recycling stream.

<https://www.plastech.biz/news/PET-cans-contaminate-plastic-recycling-stream-10623>, 2016 (accessed 12 September.2016).

[39] Food Packaging Forum, France bans BPA. Second phase of the BPA ban includes all packaging, containers and utensils coming into contact with food.

<http://www.foodpackagingforum.org/news/france-bans-bpa>, 2015 (accessed 27

March.2015).

[40] Modern Testing Services (MTS), Summary of Bisphenol A (BPA) Regulation (2nd Edition). <http://www.mts-global.com/en/technical_update/CPIE-018-13.html>, 2013 (accessed 27 March.2015).

[41] Commission Directive 2002/72/EC relating to plastic materials and articles intended to come into contact with foodstuffs, p. 4 September 2002.

[42] Product Safety Australia, Phthalates in consumer products.

<https://www.productsafety.gov.au/content/index.phtml/itemId/972486>, 2016 (accessed 28

February.2016).

[43] European Parliament News, Don't allow recycling of plastics that contain toxic phthalate DEHP, warn MEPs. <http://www.europarl.europa.eu/news/en/news-

room/20151120IPR03616/Don\%E2\%80\%99t-allow-recycling-of-plastics-that-contain-toxicphthalate-DEHP-warn-MEPs>, 2015 (accessed 28 February.2016).

[44] H.A. Leslie, P.E.G. Leonards, S.H. Brandsma, J. de Boer, N. Jonkers, Propelling plastics into the circular economy - weeding out the toxics first, Environment International (2016).

[45] IISD Reporting Services, Summary of the Montreal Protocol Meetings in Vienna, 15-23

July 2016, Vienna International Centre (VIC), Vienna, Austria, Earth Negotiations Bulletin (ENB) 19(125) (2016).

[46] B.K. Fishbein, Germany. Garbage, and the Green Dot: Challenging Ihe Throwaway Society, Inform, Inc 1994.

[47] United Nations, The United Nations Agreement for the Implementation of the Provisions of the United Nations Convention on the Law of the Sea of 10 December 1982 relating to the Conservation and Management of Straddling Fish Stocks and Highly Migratory Fish Stocks, 1995, p. 11 November 2001.

[48] United Nations Environment Programme (UNEP), Global Programme of Action for the Protection of the Marine Environment from Land-based Activities (GPA), 1995.

[49] Helsinki Commission, Baltic Marine Environment Protection Commission, Convention on the Protection of the Marine Environment of the Baltic Sea Area, 1992, p. 17 January 2000.

[50] Convention for the Protection of the Marine Environment of the North-East Atlantic, 1992, p. 25 March 1998. 
[51] United Nations, Stockholm Convention on Persistent Organic Pollutants, 2001, p. 17 May 2004.

[52] World Trade Organization, General Agreement on Tariffs and Trade [GATT], 1947, p. 1 January 1948.

[53] Rotterdam Convention on the Prior Informed Consent Procedure for Certain Hazardous Chemicals and Pesticides in International Trade, opened for signature Rotterdam PIC Convention, B7 p. 998:68 TRE-001280 (entered into force 24 February 2004) ('Rotterdam PIC Convention') <http://www.ecolex.org/server2.php/libcat/docs/TRE/Full/En/TRE001280.pdf $>$.

[54] Minamata Convention on Mercury, opened for signature 10 October 2013, B7 p. 2013:75 TRE-160007 ('Minamata Convention on Mercury')

<http://www.ecolex.org/ecolex/ledge/view/RecordDetails?index=treaties\&id=TRE-160007>. [55] North American Free Trade Agreement (NAFTA), p. 1 January 1994.

[56] PlasticsEurope, Plastics - the Facts 2014. An analysis of European plastics production, demand and waste data, 2014. 